\title{
CHALLENGES OF ONLINE-EDUCATION: WHAT SOCIETY EXPECTS FROM TEACHERS
}

\author{
Oksana Zhukova \\ Kharkiv National University named after V. N. Karazin, Ukraine \\ Lyudmila Ivanenko \\ Kharkiv National University named after V. N. Karazin, Ukraine \\ Vladimir Mandragelya \\ State University of Telecommunications, Ukraine
}

Gintaras Janužis

Lithuanian university of health sciences, Lithuania

\begin{abstract}
The main idea of the article is to present some characteristics of social expectations of teachers' work that appeared after March 2020 when the whole world found itself in online education. These expectations are rather unified and do not depend on the level of economic development of the country or the degree of involvement in providing educational services online in the pre-Covid period. The article also attempts to analyse the challenges that teachers face while providing educational services online by dividing them in 3 groups: challenges related to students; challenges related to teachers, and challenges related to external factors. As the basis for the research, the results of an anonymous survey of teachers and lecturers from 6 countries were used. The results of the study show that social expectations and social requirements set for teachers and the education system in general by the society in the context of forced and total online education are excessive For writing the article, both theoretical (analysis, observation, reflection, etc.) and empirical (survey, static processing) research methods were used.
\end{abstract}

Keywords: challenges; e-education; online education; psychological unreadiness; social expectations.

\section{Introduction}

The Coronavirus pandemic turned up to be a real challenge for every wellestablished social schemes and models for organizing life and human activities without exception. On the one hand, protracted quarantine and self-isolation as a social phenomenon showed the vulnerability of medicine, economics, public administration and education as existing systems. However, on the other hand, the need to continue life and work, even in such conditions, led to a sharp appearance or activation of forms that before Corona were only under development. 
When after March 2020 the world found itself in the online space as the main accessible reality, many problems of everyday life became sharp and needed to be resolved immediately. One of these problems is the organization of the educational process. Although the combination of "online education + learning process" has been viewed as highly promising since the beginning of the computerization era (early 1990s), for most practicing teachers this type of education remains a wonderful addition to the classroom process (Tuomi, 2018). Recognizing online education as the main source in providing educational services for children who have difficult access to regular school education (hardto-reach areas of residence, long-term stays in a hospital or prison, congenital or acquired physical or psychological inability for a child to attend educational institutions and children's team, etc.), in narrow-profile training for adult specialists, in gaining additional and highly specialized knowledge (Marr, 2019), etc., this form is not considered by practicing teachers, parents, society as the basic one for all the participants.

The article aims to analyze the existing challenges that emerged during the period of active use of online education as the only form of education, and which arose as a result of the imbalance between the requirements and expectations that society presents to the education system in general and teachers in particular, and those opportunities that are really are available for teachers in the online education space. To determine the size and main positions of this imbalance, an online anonymous survey of teachers, students, parents of students in 6 countries (Ukraine, Latvia, China, Poland, Georgia and the Czech Republic) was carried out.

\section{Literature Review}

Today, it is already possible to identify main issues and problems of online education as the main method and form of providing educational services as the world is experiencing this education reality to one degree or another for a year already. They can be presented as following:

- $\quad$ general issues and trends of online space opportunities in the provision of educational services or "cyber education" (machine learning) as a pedagogical trend - present the idea that in the modern world online education is an organic part of the educational process in particular as a result of all spheres of life digitalization in modern society (Tuomi, 2018);

- $\quad$ use of online education opportunities in teaching exact sciences and disciplines (mathematics, physics, chemistry, drawing, astronomy, etc.) - today is probably the most developed problematics as to online 
education in general. Since the exact sciences are the most logical and algometric ones, they became natural basis for testing the idea of using online education as a form of providing educational services and a lot of simulators are made all over the world (LeCun, et., 2015);

- online education as additional opportunities for secondary and higher education, highly specialized training and retraining programs for adults - based on the position that modern adolescents (the age of middle and high school, as well as students of higher educational institutions) already have collective learning skills and psychologically are more inclined to individual forms of gaining educational services, online education is almost an ideal form of getting knowledge for them (Priemer et al., 2020);

- disadvantages of online education, especially for teaching languages and educational and pedagogical work with children of preschool and primary school age who do not have formed habits of learning as a special type of activity - scientific research in this area is carried out both in the area of using online education opportunities by parents for daily developmental activities with the child (to learn colors, songs, new words, tactile exercises, etc.), as well as many books for children are published that explain to the child in the form of a fairy tale about online space and its place in the modern world (Pinango et al., 2017);

- $\quad$ artificial intelligence-based programs for self-education and advanced training online - this area was the first one which gained complete comprehensive AI based programs, that are also certified by states and are actively used in the continuing education and vocational training systems (Norvig \& Russel, 2013).

Research on other issues (online teaching and educational technologies for the elderly, people with special needs, for studying different sciences and obtaining various skills, etc.) are also underway, but today they are not as massive and fundamental as the above mentioned.

\section{Methodology}

While making the research a combination of empirical and theoretical research methods was used, that is typical for scientific studies of this kind. As to the empirical research methods, such ones as observation and comparison to analyze the background of the problematics were used. Among the methods of theoretical research, such ones as abstraction, analysis, synthesis, idealization, induction, mental modeling, ascent from abstract to concrete, etc. were used to predict and substantiate possible development options of online education 
technologies and methods from the point of view of society's social expectations as to education in general and teachers 'work in particular, challenges of online education as the dominant form of providing educational services.

To determine the existing discrepancy between social expectations and the requirements of society for the educational process online and the real capabilities of teachers and educational institutions in modern conditions (in other words, to identify "problem areas" or "challenges" of online education), an anonymous online survey of various categories of educational process participants based on a questionnaire was carried out: teachers (school and university), students, parents, administration. The sample of recipients for the survey was formed as follows: the questionnaire was proposed for consideration in educational institutions (high schools and universities). In each country, 9 educational institutions took part in the survey: students (represented 3 educational institutions), parents and administration (another 3 educational institutions), teachers and administration (another 3 educational institutions). The results obtained were processed by mathematical methods of calculation and are presented in percentage form in the article. The authors of the article understand that this sample cannot be considered indicative from a scientific point of view, but, according to the authors of the article, it gives an understanding of the issue as a whole, and can also become the basis for further research in this area.

\section{Results}

Online education is a part of the distance education system, therefore it meets all the requirements and capabilities of this particular type of pedagogical service. In particular, online education has retained such features that are typical and the same for all forms of distance education, such as:

- $\quad$ auxiliary form of education as to formal one;

- $\quad$ wide usage in non-formal education sector and in the system of industry (narrow-profiled) advanced and vocational training (therefore, initially the sphere of activity of online education is determined by adult education);

- aimed at the transfer of knowledge in the understanding of "information" (more focused on the transfer of information than on the development of practical skills);

- $\quad$ does not require a large number of teaching and learning staff;

- requires a special approach to training teachers who work online (in particular, IT training); 
- the opportunity to receive educational services from a team of professionals (teachers from different countries, researchers, practitioners, public figures, etc.) (Hockridge, 2013; Palvia et al., 2018).

It should be noted that even as a form of regular education, online education (in the form of education without the physical presence in the classroom, but through the means of communication) in the world as a social and educational reality began with universities. In 1969, the world's first online university, the Open University of Great Britain, was opened to demonstrate the non-elitism of higher education and its accessibility to all segments of the population (Palvia et al., 2018).

Today, there is a big difference between how society and the education system itself perceive online education, what are its opportunities and tasks. This is very clearly demonstrated by the results of the survey, which was conducted by the authors of this article by the method of anonymous online questionnaire held in 6 countries (Ukraine, Latvia, China, Poland, Georgia and the Czech Republic). 750 people (150 from each country) took part in the survey and they represented various categories of participants in the educational process: parents, students (secondary school graduates and students of higher educational institutions), pedagogical workers (teachers, professors and administration of educational institutions). Recipients were asked to rate 30 statements on a scale from -3 (completely disagree) to +3 (completely agree). The first block of questions was made in order to find out whether the process, goals, objectives, results, pace, etc. of the online education process should differ from the ones in traditional classroom form. For this, in particular, it was proposed to evaluate the following statement: "I believe that the transition of the educational process to the online format should not affect the volume, speed and quality of the material taught".

Table 1 The Difference in Views on the Possibilities of Online Education

\begin{tabular}{|c|c|c|c|}
\hline-3 - completely disagree & Parents & Students & Teachers \\
\hline-2 - disagree & - & 8 & 81 \\
\hline -1 - more disagree, than agree & - & 20 & 14 \\
\hline 0 - neither disagree nor agree & - & 11 & 5 \\
\hline 1 - more agree, than disagree & 6 & 49 & - \\
\hline 2 - agree & 11 & 12 & - \\
\hline 3 - completely agree & 21 & - & - \\
\hline
\end{tabular}


As it can be seen from the Table 1, the social expectations of society (which are represented by parents) and the direct subjects of the educational process (teachers and students) are fundamentally different. Parents expect from the educational process to preserve all the functions of the offline one (education in the classroom) without taking into account such features of the process as narrowing of pedagogical activity forms, methods of influencing the student, a decrease in the communicative and motivating function of education under these conditions, psycho-emotional burnout of teachers, an increase in the load both on teachers and students due to the introduction of a large number of additional documentation and forms of educational process organization (filling online courses, local educational platforms, etc.) set by the state and administration, etc. (Marr, 2019). Society still expects teachers to achieve high quality and maintain the offline pace of the educational process; using a wide range of forms, tasks, resources, types of educational activities; motivation, monitoring, control of students; taking into account the individual characteristics of each student; selfeducation and self-improvement to meet the trends that society puts forward.

Also very indicative is the fact that society mainly tries to distance itself from the problems of the educational sphere. A block of questions aimed at clarifying the role of society in the person of parents in the learning process in online conditions that are difficult for everyone showed that parents prefer to leave the educational process entirely to teachers and the state, retaining, however, the functions of monitoring and criticizing of existing practices. The following statement was proposed for the consideration: "Responsibility for the process, results and consequences of online education stays with the teachers". The following results appeared:

Table 2 Responsibility for the Process, Results and Consequences of Online Education

\begin{tabular}{|c|c|c|c|}
\hline & Parents & Students & Teachers \\
\hline-3 - completely disagree & - & 4 & 93 \\
\hline-2 - disagree & 1 & 15 & 7 \\
\hline-1 - more disagree, than agree & 5 & 36 & - \\
\hline 0 - I don't know & 9 & 39 & - \\
\hline 1 - more agree, than disagree & 5 & 2 & - \\
\hline 2 - agree & 9 & - & - \\
\hline 3 - completely agree & 71 & 4 & - \\
\hline
\end{tabular}


This position of the parents demonstrated insufficient information work of educational institutions and the state, which raise questions about the shortcomings of online education, without focusing on its features as a form of providing educational services. As a result, parents elementarily lack the information to correctly understand the processes going on in online education in order to adapt their expectations from children and the education system in general to existing realities and opportunities.

Analyzing the main difficulties (or challenges) of educational work in the online space, which were noted by teachers, administrators of educational institutions and students, all challenges were conditionally divided into 3 large groups, which we consider below.

\section{External challenges}

- weak internet or lack of it. The availability, stability and speed of the Internet network are the determining factors in the possibilities of online education and the comfort of this form of providing educational services. Unfortunately, modern realities show that this aspect to a certain extent demotivates teachers and students to constant online communication;

- the discrepancy between the gadgets used and the requirements of online education or their lack. Each country solved the problem of teachers' and students' technical equipment based on its own understanding and financial capabilities. For example, countries such as Israel and Georgia provided interest-free loans for the purchase of a certain class of computer equipment for teachers and parents of students under 20 years old, and also reduced prices (compensating for the difference in cost at the expense of the state). The PR China financed educational institutions to buy a large number of gadgets and offered students the opportunity to rent them (teachers were given gadgets for free from the educational institution). Ukraine urged teachers and parents to resolve this issue by themselves, or teachers could use school equipment on school grounds, following all quarantine requirements. Also, the level of the gadget itself and its functionality plays an important role in providing quality educational services in online education. Modern adolescents prefer mobile phones to other types of gadgets (tablets or computers) (Shi, et., 2020), that also significantly narrows the possibilities and functionality of online education as a type of educational activity.;

- lack of funding to pay for the services of online learning platforms, constructors, libraries, etc. for teachers. Indeed, the development of online education has led to the emergence of a large number of 
constructors, libraries and platforms, the work with which facilitates a lesson, allows a teacher to make the lesson brighter and more interesting due to various activities and tasks (Martin, 2019). However, such programs are mostly paid (only demo versions are available for free, which do not provide full functionality or their use is limited in time), and the education budget in most countries does not let compensations for money spent by teachers on specialized programs, constructors or libraries;

- lack of sufficient technical support staff for a teacher. Most teachers, especially those over the age of 45 , do not have the appropriate level of technical training to use all the technical possibilities of online education and related software.;

- lack of new standards for calculating hours for the preparation of classes and their conduct, rate scales, courses for teachers, etc. All teachers are faced with the fact that preparation for the lesson now takes many times longer than in the usual classroom format. This leads to a syndrome of constant fatigue among teachers, their dissatisfaction with their work (imbalance between the amount of time spent on preparation and the result achieved in the lesson), apathy for work, etc. (Kluger, 2020).

\section{Student-related factors:}

- weak disciplining influence (especially at the initial levels of education). If a student does not want, then he/she will not enter the Internet and will not join the education process. Unfortunately, in conditions of online education, the home environment itself is a demotivating and destructive factor, as it relaxes and distributes a student's attention, reduces his/her perseverance, discipline and efficiency;

- decreased communication function. The lack of opportunities for active communication during long-time online education as the only (or dominant) form of receiving educational services leads to negative factors and qualitative changes in the behaviour of students: children unlearn how to interact with each other and with the team, cease to feel as a part of a team, their personal space and personal distance expand (it becomes difficult for them to find themselves in a classroom where other students can approach them), the level of anxiety increases, etc. China was the first to encounter such manifestations on a massive scale among secondary school and university students and today it has an active policy of resocializing its youth (Shi \& Yaroschchuk, 2020); 
- decrease in motivation and interest in communication because of the educational activity forms` narrowing. Students are not interested in experiencing a narrow range of educational activities, since the group forms of work that are traditionally used in the classroom are difficult to be used in the context of online education. For the most, in online education reproductive forms of tasks during a lesson are used with an emphasis on individual ones (question-answer, speech, presentation, lecture) and a large number of homework (essays, self-familiarization with the material, etc.).

\section{Teacher-related challenges:}

- $\quad$ psychological unpreparedness and lack of habit of a teacher to see / hear him/herself online and (especially) in the recording. There are very few people in the world who are absolutely satisfied with themselves and teachers are also very critical of their appearance and natural data (voice, facial expressions, movements, etc.) (Ding \& Kalashnyk, 2020). The camera brightens up our flaws and shows them to us in full. The "audience effect" negates this factor and allows teachers to see themselves in the teaching process as they want to;

- $\quad$ psychological unwillingness to change one's own concept and model of professional activity to comply with the idea of distance and online education. As mentioned above, most teachers acquired professional skills in realities that were not related to computer education and a large number of online opportunities. They themselves studied and underwent professional development in other conditions, as a result of which they developed professional algorithms and skills, which they considered to be enough before the transition of education to the online space. Therefore, teachers came to online education with their wellestablished educational stereotypes, algorithms, representations and models. Therefore, one of the main tasks for teachers today is to adapt their skills and models to the requirements of the online process, as well as to understand the difference between the principles, objectives, goals, mechanisms of offline and online learning as forms of providing educational services (Adedoyin \& Soykan, 2020);

- narrowing of methods of pedagogical influence (monitoring, control, motivation ...) and forms of activity;

- lack of habits and skills of advanced training on online education (selfeducation, self-motivation, centralized system of advanced training);

- lack of a system of psychological support for teachers and students to solve their problems associated with professional burnout and professional deformation. 
These are far from all the challenges that society faced in connection with the transition of the education sector to the online format. And now the most important thing is to establish a dialogue between society and the education system, to balance the possibilities of online education and social expectations of society.

\section{Conclusions}

The system of providing educational services only in online format is currently in its infancy. The COVID-19 pandemic and the forced lockdown brightened the practical aspects of the process, which provoked the emergence of new forms, methods, practical approaches in education (as a positive), but also clarified the existing problems and shortcomings of the existing education system, the unpreparedness of teaching staff and society as a whole for such an educational reality. This reality has caused many challenges for society and overestimated requirements for teachers and the education system as a whole is just one of them. The reason for this is the imbalance between the possibilities of online education and the social expectations and requirements of society, which were formed on the basis of knowledge transfer offline process. To work with these challenges positively it requires an active dialogue between society and the education system, more information about the features and practical mechanisms, as well as goals and objectives of online education as a form of providing educational services. Also, a lot of work is required to change the approaches to training, retraining and psycho-emotional support of teachers in order to quickly match them with the possibilities of online education.

\section{References}

Adedoyin, O., Soykan, E. (2020). Covid-19 pandemic and online learning: the challenges and opportunities. Interactive learning environments. DOI: https://doi.org/10.1080/ 10494820.2020.1813180

Ding, S., \& Kalashnyk, L. (2020). Resocialization and Readaptation as a Social Need of PostCorona Period. Postmodern Openings, 11 (1Supl2). DOI: https://doi.org/10.18662/ po/11.1sup2/135

Hockridge, D. (2013). Challenges for educators using distance and online education to prepare students for relational professions. Distance Education, 34, 142-160. DOI: 10.1080/01587919.2013.793640

Kluger, J. (2020). The Coronavirus pandemic may be causing an anxiety. Time. pandemic. March. Retrieved from: https://time.com/5808278/coronavirus-anxiety/

LeCun, Y., Bengio, Y. \& Hinton, G. (2015). Deep learning. Nature, 521 (7553), 436-444. Retrieved from: https://www.nature.com/articles/nature14539 
Proceedings of the International Scientific Conference. Volume V, May $28^{\text {th }}-29^{\text {th }}$, 2021. 522-532

Marr, B. (2019). How Is AI Used In Education - Real World Examples Of Today And A Peek Into The Future. Forbes. Retrieved from: https://bernardmarr.com/default.asp? contentID $=1541$

Martin, S. (2019). Artificial Intelligence, Mixed Reality, and the Redefinition of the Classroom. Rowman \& Littlefield.

Norvig, P. \& Russel, S. (2013). Artificial Intelligence: a modern approach. Pearson Education Limited.

Palvia, S., Aeron, P., Gupta, P., Mahapatra, D., Parida, R., Rosner, R. \& Sindhi, S. (2018). Online Education: Worldwide Status, Challenges, Trends, and Implications. Journal of Global Information Technology Management. https://doi.org/10.1080/1097198X. 2018.1542262

Pinango, M., Zhang, M., Foster-Hanson, E., Negishi, M., Lacadie, C., Costable, R.T. (2017). Metonymy as Referential dependency: psycholinguistic and neurolinguistic arguments for a unified linguistic treatment. Cognitive science. Multidisciplinary Journal, 41, 351378. DOI: 10.1111/cogs.12341

Priemer, B., Eilerts, K., Filler, N., Pinkwart, N., Rosken-Winter, B., Tiemann, R., Upmeier zuBelzen, A. (2020). A framework to foster problem-solving in STEAM and computing education. Research in Science and Technological Education, 38 (1), 105-130. DOI: https://doi.org/10.1080/02635143.2019.1600490

Shi, Y., \& Yaroschchuk, L. (2020). Post Corona Society: How to Teach People be Social Again. Postmodern Openings, 11 (1Supl2). DOI: https://doi.org/10.18662/po/11.1sup2/149

Tuomi, I. (2018). The Impact of Artificial Intelligence on Learning, Teaching, and Education. Policies for the future. Luxembourg: Office of the European Union. 